\title{
GENE DELIVERY TO THE RETINA USING LENTIVIRAL VECTORS
}

\author{
Kenneth P. Greenberg ${ }^{1,2}$, Edwin S. Lee ${ }^{2,3}$, David V. Schaffer ${ }^{2,4}$ and \\ John G. Flannery ${ }^{1,2}$
}

\section{INTRODUCTION}

The delivery of foreign DNA to the retina has proven to be a valuable tool for investigations of retinal disease, development, and complex cellular interactions. To achieve efficient and stable retinal gene expression with minimal unwanted side effects, viral vectors derived from AAV (adeno-associated virus) and LV (lentivirus) remain the vehicles of choice. LV vectors have gained recent attention in CNS gene delivery due in part to their large transgene capacity, however contradictory results regarding retinal transduction ability exist in the literature. We sought specifically to characterize the temporal and spatial expression pattern of LV vectors when delivered to the rodent retina.

The primary goals in the development of gene transfer vectors have been to harness a virus's innate ability to deliver a gene payload to a cell, while eliminating any pathogenic potential of that virus. Evolution has cleverly accomplished the former, while the latter has been achieved through the selective removal of wild type replication and virulence genes $^{1,2}$. Current vectors are both safe and efficient vehicles for gene transfer to the primate retina ${ }^{3,4}$ and phase I human clinical trials are underway ${ }^{5}$.

\section{LENTIVIRAL VECTOR DESIGN AND BIOSAFETY}

Lentiviruses are a type of retrovirus capable of infecting both dividing and nondividing cells due to their unique ability to pass through a target cell's intact nuclear membrane, an essential property for CNS gene transfer. LV vectors have many desirable

${ }^{1}$ Vision Science, ${ }^{2} \mathrm{Helen}$ Wills Neuroscience Institute, ${ }^{3}$ Molecular and Cell Biology, and ${ }^{4}$ Chemical Engineering, University of California, Berkeley, CA 94720, USA; Corresponding author: K. P. Greenberg, E-mail: kgreenb@berkeley.edu 
features including a large transgene carrying capacity ( $\sim 8 \mathrm{~kb}$ vs. AAV's $4.8 \mathrm{~kb})$ and stable integration leading to long-term expression. Adenovirus (Ad) vectors have an exceedingly large capacity $(36 \mathrm{~kb})$, however their lack of stable integration results in transient expression. LV vectors also have the apparent ability to avoid immune system inactivation, a current handicap of both Ad and AAV vectors. The most frequently used LV vectors are based on HIV-1, however vectors derived from non-human lentiviruses such as FIV (feline immunodeficiency virus), SIV (simian immunodeficiency virus), BIV (bovine immunodeficiency virus) and EIAV (equine infectious anemia virus) could theoretically provide biosafety advantages ${ }^{6-9}$.

An obvious concern for the delivery of HIV based vectors to humans is the potential for AIDS or an AIDS-like disease caused by a replication competent vector. This concern has been addressed by completely deleting six (env, tat, vif, vpr, vup, and nef) of the nine viral genes, keeping only those essential for gene delivery (gag, pol, and rev). Furthermore, any potential replication competent recombinant (RCR) vectors can be screened for by sensitive methods ${ }^{10,11}$. A second safety issue concerns the inadvertent activation of celluar oncogenes from transcriptional read-through of the HIV long terminal repeat promoter (LTR). Deletion of the 3' LTR core promoter and replacement of the wild type U3 region of the 5' HIV LTR with the cytomegalovirus (CMV) promoter in the current third generation of self-inactivating (SIN) vectors results is an integrated provirus with transcriptionally silent LTRs and no viral genes ${ }^{12}$.

Recent improvements in LV vector delivered transgene expression levels have been achieved by two methods. First, incorporation of the HIV central polypurine tract (CPPT) sequence upstream of the desired payload appears to enhance nuclear entry of the preintegration complex and significantly increases expression levels ${ }^{13}$. Although the precise role of the CPPT is debated ${ }^{14,15}$, our results indicate that this element increases transgene expression levels in the retina (data not shown). Secondly, incorporation of the woodchuck hepatitis virus post-transcriptional regulatory element (WPRE) downstream of the transgene enhances stability of the RNA transcript and therefore increases expression levels ${ }^{16}$. An HIV-1 based transfer vector containing these elements is shown (Fig. 1).

\section{TARGETING LENTIVIRAL VECTORS}

Much effort is currently underway to specifically target all classes of neural, glial, and epithelial cells in the retina with viral vectors. However, photoreceptors, RPE, and ganglion cells remain the only retinal cell types successfully targeted with LV vectors ${ }^{17-}$

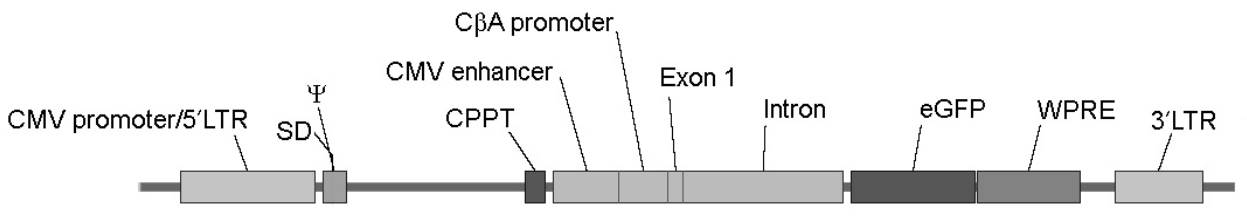

Figure 1. HIV-1 based lentiviral transfer vector (pFCßAGW) containing SIN LTRs, CPPT, hybrid CMV enhancer/Chicken $\beta$-Actin promoter (including exon 1 and the intron) driving eGFP, and WPRE. 
19. Presently, the efficiency of delivery to photoreceptors and ganglion cells remains significantly higher with AAV vectors than LV vectors.

Methods for targeting specific cell types (altering the tropism of a virus) can be divided into two basic categories: restricting viral entry at the point of transduction or restricting transgene expression at the stage of transcription. Ideally, one could limit vector entry to a desired class of cell, therefore eliminating potential off-target effects. Although it has been attempted with LV vectors, transductional targeting has been met with limited success ${ }^{20}$. Ongoing research aimed at genetically inserting cell specific peptides into the envelope or discovering mutants with novel tropisms will likely resolve these difficulties.

Enveloped viruses such as lentiviruses may utilize envelope glycoproteins derived from other enveloped viruses. Pseudotyping, or the replacement of one virus's envelope glycoproteins with those from another virus, has been effective for increasing vector host cell range, increasing vector particle stability, and limiting vector entry to certain types of cells ${ }^{21-23}$. The majority of LV vectors used in retinal gene transfer are pseudotyped with envelope glycoproteins derived from the vesicular stomatitis virus (VSV) glycoprotein, although other pseudotypes have been tested ${ }^{24,}{ }^{25}$. Novel vector pseudotypes are frequently discovered which may have the innate ability to target certain cell types while maintaining their highly evolved and efficient delivery characteristics ${ }^{26}$.

In addition to pseudotyping, transcriptionally targeting specific cell types has been used with great success in the CNS. Cell specific regulatory elements inserted upstream of the transgene can direct expression to photoreceptors, hippocampal neurons, and astrocyte $^{27-29}$. Transcriptional targeting is increasingly feasible due to the ongoing identification of cell specific promoters for virtually all classes of cells in the retina.

\section{METHODS}

\subsection{Vector Production}

All procedures involving vector production, concentration, and titration were performed in a Type IIA biosafety cabinet under strict BL2 practice. LV vectors were produced by either calcium phosphate or Lipofectamine 2000 (Invitrogen) transient transfection.

Calcium phosphate transfections were adapted from a previous protocol ${ }^{1}$ and performed as follows. Five T-175 (Nunc) flasks were coated with poly-L-lysine (Sigma \#P4832 diluted 1:10 in PBS and sterile filtered) and allowed to stand for 10 minutes before aspirating. Low passage 293T cells (ATCC \#CRL-11268) were seeded at 1.2$1.5 \times 10^{7}$ cells per flask in $20 \mathrm{~mL}$ complete IMDM (IMDM $+10 \%$ FBS, 1 XPen/Strep, $2 \mathrm{mM}$ L-glutamine). The following day the calcium phosphate/DNA precipitate was prepared after all reagents equilibrated to room temperature. For five T-175 flasks, $158 \mu \mathrm{g}$ transfer vector (pCS-CG or pFC $\beta A G W$ ), $79 \mu \mathrm{g} \mathrm{pMDLg} / \mathrm{pRRE}, 24 \mu \mathrm{g} \mathrm{pRSV}-\mathrm{REV}$, and $55 \mu \mathrm{g}$ pMD.G (VSVG) were mixed in a final volume of $13.9 \mathrm{~mL}$ sterile $\mathrm{ddH}_{2} \mathrm{O}$ (buffered with Hepes to $2.5 \mathrm{mM}$ ) and $1.9 \mathrm{~mL} 2.5 \mathrm{M} \mathrm{CaCl}_{2}$. After mixing, $15.8 \mathrm{~mL} 2 \mathrm{X}$ HeBS (Hepes Buffered Saline $\mathrm{pH}$ 7.05) was added to the DNA/ $\mathrm{H}_{2} \mathrm{O} / \mathrm{CaCl}_{2}$ solution and mixed by pipetting briefly. The $\mathrm{CaPO}_{4}$ precipitate formed during a 1.5 minute incubation, and the 
reaction was quenched by adding $18.4 \mathrm{~mL}$ complete IMDM media. After mixing briefly, $10 \mathrm{~mL}$ of this solution was added to each flask which was placed in an incubator $\left(37^{0} \mathrm{C}\right.$, $5 \% \mathrm{CO}_{2}$ ) overnight. Media was aspirated and replaced with $20 \mathrm{~mL}$ fresh IMDM 12 hours later. Two harvests of the cell supernatant were performed 24 hours and 48 hours after the first media change. The cell supernatant $(200 \mathrm{~mL})$ was then filtered through a $0.45 \mu \mathrm{m}$ pore PVDF Durapore filter (Millipore, Bedford, MA) and stored at $4^{0} \mathrm{C}$ until concentrated.

For Lipofectamine 2000 transfections, 293T cells were plated as described in complete IMDM lacking antibiotics. We found that for optimal transfections, the total amount of plasmid DNA can reduced by 2.25 fold, while maintaining the above ratio of four plasmids. Transfection complexes were prepared by mixing the plasmids in a final volume of $21.9 \mathrm{~mL}$ Opti-MEM reduced serum media (Invitrogen). In a separate reaction tube, $21.4 \mathrm{~mL}$ Opti-MEM media was gently mixed with $525 \mu \mathrm{L}$ Lipofectamine 2000 reagent. Both tubes were incubated at room temperature for 5 minutes, gently mixed together, and incubated another 20 minutes. This solution was added to each of the five flasks which were placed in an incubator overnight. Transfection media was aspirated 12 hours later, cells were washed with PBS, and given $20 \mathrm{~mL}$ complete IMDM. The additional PBS wash was found necessary to remove transfection amine complexes which frequently caused cataracts when carried over into the injected vector preparation. Vector supernatant was harvested and filtered as described above.

\subsection{Vector Concentration for In Vivo Use}

High titer LV vector stocks were generated after two rounds of ultracentrifugation. The filtered vector supernatant $(32 \mathrm{~mL})$ was carefully overlaid on a $20 \%$ sucrose solution $(4 \mathrm{~mL})$ in six ultracentrifuge tubes (Beckman \#344058) which were centrifuged at 24,000 $\mathrm{rpm}$ in a SW-28 rotor for 2 hours at $4^{0} \mathrm{C}$. The supernatant was aspirated (avoiding the pellet) and $800 \mu \mathrm{L}$ cold PBS was added to each tube and mixed by pipetting. After a 30 minute incubation on ice, the six vector/PBS tubes were pooled and overlayed on $1 \mathrm{~mL}$ of $20 \%$ sucrose in one ultracentrifuge tube (Beckman \#344059). The vector was centrifuged in a SW-41Ti rotor at $25,000 \mathrm{rpm}$ for 1.5 hours at $4^{\circ} \mathrm{C}$. The supernatant was aspirated and pelleted vector was resuspended in $200 \mu \mathrm{L}$ cold PBS. Vector was incubated on ice overnight and again mixed by pipetting. If not used immediatedly, vector was stored for up to one week at $4^{0} \mathrm{C}$ or flash frozen and stored at $-80^{\circ} \mathrm{C}$ for long term.

\subsection{Vector Titer Determination by Q-PCR}

Both physical particle and functional biological titers may be determined by several methods including p24 ELISA, FACS, and quantitative PCR $^{30,31}$. A particle titer estimates the amount of vector present in a preparation, however it provides no information regarding the biological function of a vector. Conversely, functional titer determination can accurately estimate the infectious ability of a vector through the quantitative detection of integrated proviral genomes by real time PCR. This method has the advantage of isolating the viral transduction event from later gene trancription and translation, which is the basis for protein expression titers (FACS). Although time consuming, one clear benefit to this approach is the ability to determine vector titer on a cell line (ie 293s) irrespective of the vector delivered promoter element. Vectors may 
contain cell specific promoters whose gene product is not expressed in an available cell line, and therefore titer determination based on protein expression is not feasable. Additionally, we find this method invaluable for testing vector transduction efficiency of pseudotyped or engineered vectors on primary retinal cell isolates regardless of promoter.

Functional titer was determined based on a protocol ${ }^{31}$ by quantitative PCR as follows. Cultured $293 \mathrm{~T}$ cells were infected with serial dilutions of vector $\left(10^{-3}-10^{-7}\right)$ in $1.0 \mathrm{~mL}$ media with $8 \mathrm{ug} / \mathrm{mL}$ polybrene in a six well plate $\left(2-5 \times 10^{5}\right.$ cells/well). Cells were incubated for at least 4-5 days and washed multiple times to remove residual plasmid carried over from vector production. The transduced cells were then trypsinized, counted, and DNA from $1 \times 10^{6}$ cells from each well was isolated (Gentra Puregene \#D-5000A). The total amount of DNA from each sample was normalized and $5 \mu l$ was added to each Q-PCR reaction (ABI \#N808-0228) containing 3.5mM $\mathrm{MgCl}_{2}, 200 \mu \mathrm{M}$ each DNTP, $320 \mathrm{nM}$ each primer, $320 \mathrm{nM}$ probe, $0.025 \mathrm{U} / \mu \mathrm{L}$ amplitaq, $2.5 \mu \mathrm{L}$ reaction buffer, and $\mathrm{ddH}_{2} \mathrm{O}$ to $25 \mu \mathrm{L}$. Primers (Fwd-ACCTGAAAGCGAAAGGGAAAC, Rev-CACCCATC TCTCTCCTTCTAGCC) and probe (5'FAM-AGCTCTCTCGACGCAGGACTCGGCBHQ-3' Biosearch Technologies) sequences are specific to the HIV-1 packaging signal ( $\psi)$ and may be used with any HIV-1 based vectors containing this element. A standard curve was generated by amplification of a spectrophotometrically predetermined quantity $\left(10^{10}-10^{2}\right.$ molecules/reaction) of transfer vector plasmid containing the HIV-1 packaging sequence.

Each reaction was performed in triplicate under the following conditions in a Stratagene Mx-3000P thermocycler: 1 cycle of $95^{\circ} \mathrm{C}$ for 10 minutes, 40 cycles of $95^{\circ} \mathrm{C}$ for 15 seconds and $60^{\circ} \mathrm{C}$ for 2 minutes. The thermocycler was set to detect and report fluorescence during the annealing/extension step of each cycle. A standard curve was generated by plotting theshold cycles vs. copy number and vector DNA titer in TU/mL (transducing units $/ \mathrm{mL}$ ) was determined at multiple dilutions (Fig. 2).

An RNA based particle titer may also be determined using Quantitative Reverse Transcriptase PCR (QRT-PCR). Serial dilutions of vector stock were prepared in PBS, RNA was extracted (QIAamp MinElute Virus Kit Qiagen \#57714), and residual DNA removed while RNA was bound to the purification column (Qiagen Rnase-Free Dnase set
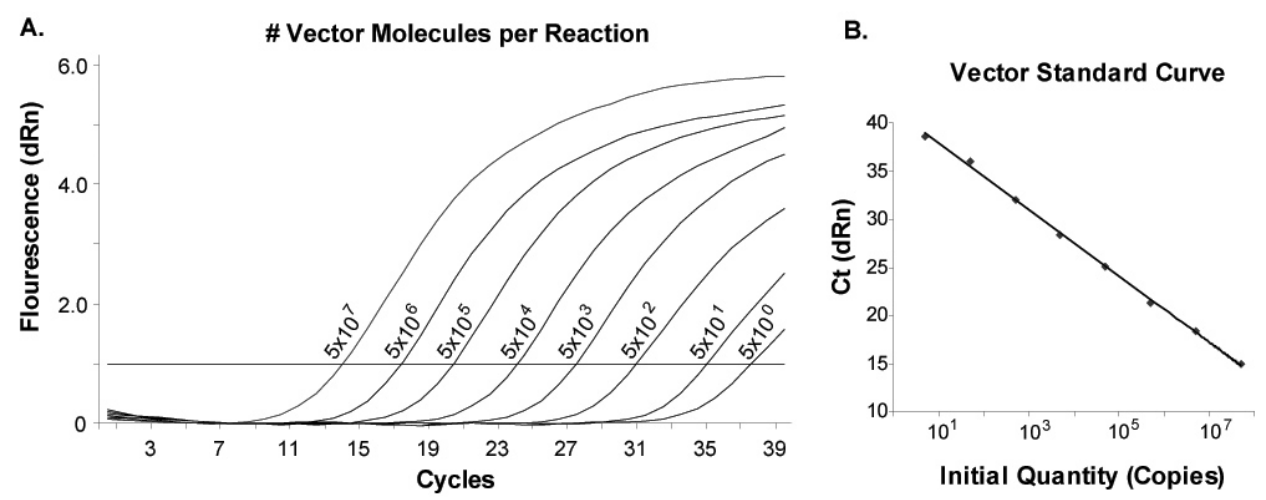

Figure 2. Q-PCR Amplification plot of pCS-CG plasmid (A), and standard curve (B) generated by plotting threshold cycle $(\mathrm{Ct})$ against number of vector DNA molecules. 
\#79254). QRT-PCR reactions (Stratagene Brilliant QRT-PCR Master Mix Kit \#600551) were prepared as follows: 1X QRT-PCR Master Mix, 320nM each primer (see above), $320 \mathrm{nM}$ probe (see above), $0.375 \mu \mathrm{L}$ of 1:500 diluted reference dye, $0.1 \mu \mathrm{L}$ StrataScript $\mathrm{RT} / \mathrm{Rnase}$, and $\mathrm{ddH}_{2} \mathrm{O}$ to $25 \mu \mathrm{L}$. Reactions were performed in triplicate and reactions lacking RT were used to determine backgound DNA amplification. Cycling conditions were as described above with the addition of an initial $48^{\circ} \mathrm{C}$ RT cycle for 30 minutes. RNA titer was determined by using transfer vector plasmid as the standard after subtracting out background signal from the reactions lacking RT.

\subsection{Intraocular Injection Procedure}

All procedures used were in accordance with the ARVO Statement for the Use of Animals in Ophthalmic and Vision Research and were approved by the University of California, Berkeley Committee on Animal Research. C57BL/6 mice and SpragueDawley rats were used in all the studies. For LV time course studies, C57BL/6 mice aged between P4-P17 were used. Animals were anesthetized by intraperitoneal injection of ketamine/xylazine and eyes were dilated using $2.5 \%$ phenylephrine hydrochloride and $1 \%$ atropine sulfate. A shelving puncture was made through the sclera with a sharp 30gauge needle, followed by a Hamilton syringe equipped with a blunt 33-gauge needle. For subretinal injections, the tip of the needle was advanced through the sclera, choroid, retina, and vitreous, and the needle penetrated the superior central retina to deliver the vector $(0.5-3 \mu \mathrm{L})$ into the subretinal space. We found this approach to be most successful in avoiding damage to the lens. Intravitreal injections were performed by delivering the vector $(2-10 \mu \mathrm{L})$ directly into the vitreous body. Immediately after injection, the quality (ie. lack of hemorrhage) and size of the subretinal bleb were evaluated under a stereo microscope by visualizing through a cover slip with Celluvisc (Allergan, Irvine, CA) placed on the cornea.

\subsection{In Vivo GFP Imaging}

GFP expression was evaluated in vivo 3-60 days after injection of LV vectors. A Retcam II (Massie Research, Pleasanton, CA) was used for fluorescent and visible light fundus imaging in live anesthetized rodents. The Retcam II is a contact fiber-optic, digital, color fundus camera originally developed for wide-field pediatric retinal imaging. The RetCam II is based around a 3 CCD medical grade digital camera providing high resolution 24 bit color images and a 20 second real time video capture mode. The Retcam II's handheld camera unit and foot controlled focus and incident light intensity made imaging the immobilized rodent retina an extremely rapid and efficient procedure. In vivo imaging was performed on anesthetized rodents with dilated pupils, while using Genteal gel (Novartis Opthalmics, Duluth, GA) as a contact medium between the camera lens and the rodent's cornea. The onset, duration, and extent of GFP expression was tracked in this manner. Additionally, the Retcam II was extremely useful for imaging subretinal detachments immediately after LV vector delivery. 


\subsection{Tissue Preparation}

Eyes were enucleated from animals injected with LV-CMV-GFP or LV-C $\beta A-G F P$ at 10-60 days post-injection. Eye cups were fixed in 4\% paraformaldehyde in PBS for 1 hour at $4^{0} \mathrm{C}$ and washed in PBS. Eyes were cryoprotected in $15 \%$ sucrose for 2 hours followed by $30 \%$ sucrose overnight at $4^{0} \mathrm{C}$, embedded in OCT, and flash frozen in a dry ice/ethanol slurry. Sections were cut $(10 \mu \mathrm{M}$ thick) using a CM1850 cryostat (Leica, Nussloch, Germany) and were thaw mounted on Superfrost Plus slides (Fisher Scientific). Images were acquired using a Zeiss Axiophot epifluorescence microscope (Thornwood, NY).

\section{RESULTS}

\subsection{Q-PCR Vector Titers}

DNA based functional vector titers in the cell supernatant ranged from $5 \times 10^{6}-2 \times 10^{7}$ $\mathrm{TU} / \mathrm{mL}$ before and $7 \times 10^{8}-1 \times 10^{10} \mathrm{TU} / \mathrm{mL}$ after concentration. RNA based particle titers were $3 \times 10^{8}-8 \times 10^{9}$ particles $/ \mathrm{mL}$ in the supernatant, and $6 \times 10^{10}-2 \times 10^{12}$ particles $/ \mathrm{mL}$ after concentration. Taking the difference between RNA and DNA titers, we found the functional vector:inactive particle ratio to be from 1:100 to 1:1000. GFP titers were also determined by direct visualization for some vector batches and were found to be slightly lower than Q-PCR determined functional titers. Titers of vectors produced by Lipofectamine 2000 transfection were routinely higher than those produced by calcium phosphate transfection.

\subsection{In Vivo GFP Expression}

GFP expression was detectable within 3 days after injection and persisted for at least 6 months. When delivered in a subretinal injection to adult animals, we found VSVCMV-GFP and VSV-C $\beta A$-GFP vectors to have a strong cellular tropism for the RPE. Intravitreal delivery of LV was inefficient and resulted in occasional expression in cells of the GCL (not shown). Retcam II imaging revealed GFP expression covering a large surface area after subretinal LV injection with little indication of retinal trauma (Fig. 3A). Of the five available interchangeable lenses, we found the Retcam II equipped with a wide angle 130 degree ROP lens to provide extremely sharp fundus images of the rat retina (Fig. 3B). A high contrast 80 degree lens provided satisfactory images in large mouse eyes, although shadowing was apparent around the retinal periphery in smaller mouse eyes.

Most interestingly, we found that when delivered subretinally to young mouse pups aged P4 and P7, the VSV-CMV-GFP LV vector transduced photoreceptors in addition to the RPE layer (Fig. 4A and 4B). Photoreceptor transduction in these young animals was present primarily at the injection site. GFP expression was highly restricted to the RPE layer in all mice aged P10, P14, and P17 (Fig. 4C). Mild evidence of an immune response at the injection site was observed in 2 of the 24 injected animals (Fig. 4D). PBS injected 
control animals exhibited no obvious immune response. GFP expression extended over the majority of the RPE (Fig. 4E).

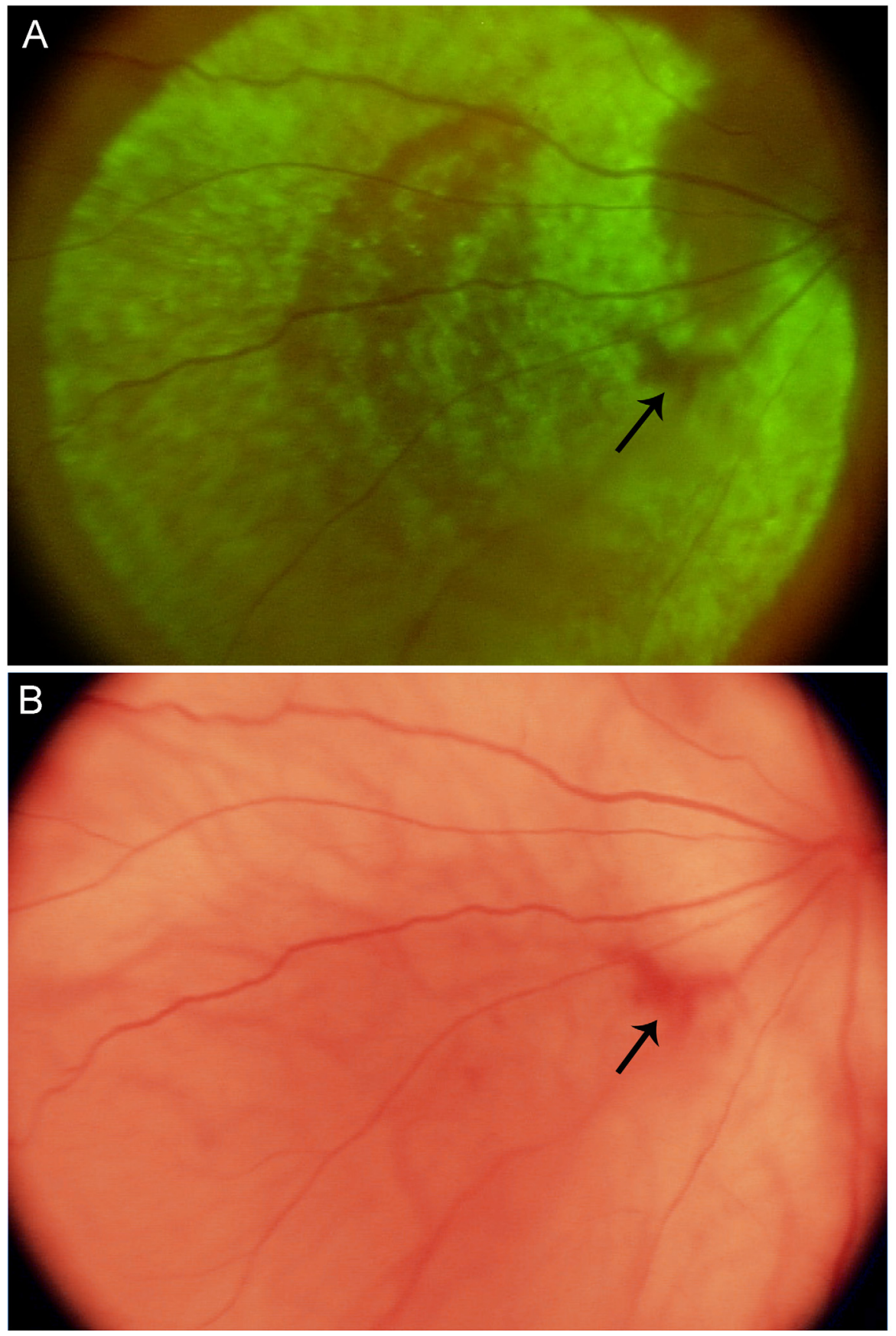


Figure 3. Flourescent fundus image showing widespread GFP expression in rat retina 1 week after subretinal injection of $3 \mu \mathrm{L}$ VSV-C $\beta A$-GFP lentiviral vector (A). Fundus image of same rat under white light illumination (B). Arrows indicate small hemorrhage resulting from subretinal injection. Both images acquired with a Retcam II imaging system (Massie Research, Pleasanton, CA).
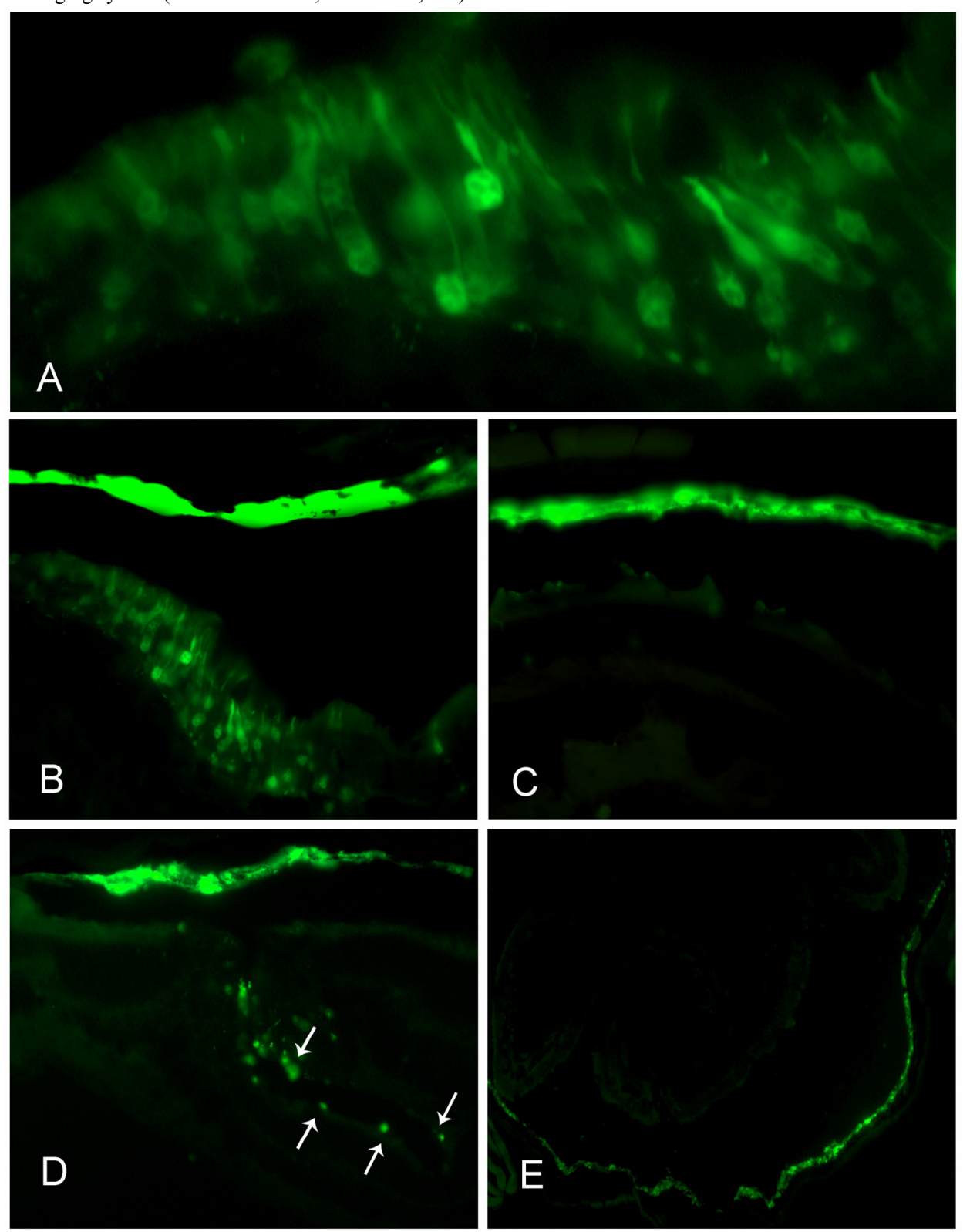

Figure 4. High magnification view of GFP positive photoreceptors of mouse retina injected subretinally with VSV-CMV-GFP LV vector at age P7 (A). Lower magnification view (B) of the same retina shown in (A) where RPE and photoreceptors are seen expressing GFP. Expression of GFP restricted to the RPE layer in P14 mouse retina injected with VSV-CMV-GFP LV vector (C). Injection track mark shown (arrows) and evidence of 
immune response from autoflourescent macrophages bordering track mark (D). Low magnification view showing extent of GFP expression along entire length of the RPE (E).

\section{DISCUSSION}

We aimed to determine the cellular tropism of VSV-LV vectors when injected subretinally in rodents. An inconsistency exists in the literature where some reports show that VSV-LV efficiently transduces both photoreceptors and RPE, while others show RPE restricted expression ${ }^{17,18,32}$. To better understand the capability of this vector, we sought to clarify the temporal tropism for photoreceptor transduction when delivered to young mice pups.

A developmental window was found to exist for the VSV-LV vector's ability to transduce photoreceptors when subretinally injected into C57BL/6 mice. This vector readily transduced RPE cells in mice of all ages, however transduction of photoreceptors occurred only in mice aged P7 and younger. The temporal window for photoreceptor transduction coincides with a period of rod photoreceptor neurogenesis during retinal development $^{33}$. The onset of RPE specific transduction coincides with the completion of photoreceptor development and the beginning of normally occurring photoreceptor death $^{34}$.

Binding and fusion of the VSV-LV vector does not appear to depend on the presence of specific cell surface receptors, therefore this tropism is unlikely the result of transient surface receptor expression on photoreceptors during development ${ }^{35}$. The relatively unorganized architecture of the immature mouse retina may facilitate viral access to photoreceptor cells. The mechanism for this restricted tropism is not entirely understood, however it appears to be related to the restricted access of the viral particles to photoreceptors probably due to the protein rich (Chondroitins, collagen, and fibronectin) inter-photoreceptor matrix (IPM). Enzymatic digestion of the IPM appears to improve $\mathrm{LV}$ vector access to photoreceptors ${ }^{36}$. Additionally, direct RPE phagocytosis of LV vector could play an important role in high RPE transduction.

In some cases, such as the secretion of therapeutic growth factors, ubiquitous expression may be desired in as many retinal cell types as possible. LV vectors containing "ubiquitous" promoters such as CMV, CMV- $\beta$-actin, EF1- $\alpha$, PGK, and ubiquitin have been tested in the retina. Although excellent tools for strong expression in the RPE, these "ubiquitous" promoters should be regarded with care as they demonstrate specific, rather than universal spatial expression patterns when delivered subretinally by LV vectors.

Current and future efforts to target specific classes of retinal cells with LV vectors will be particularly useful for the treatment of retinal degenerative diseases through gene therapy.

\section{ACKNOWLEDGEMENTS}

The authors wish to thank Scott Geller, Natalie Walsh, and Josh Leonard for procedural advice, Debbie Kuo and Aaron Pham for technical assistance, and the Foundation Fighting Blindness for their travel support of KPG to attend the RD2004 meeting. 


\section{REFERENCES}

1. L. Naldini, U. Blomer, P. Gallay, D. Ory, R. Mulligan, F. H. Gage, I. M. Verma and D. Trono, In vivo gene delivery and stable transduction of nondividing cells by a lentiviral vector, Science. 272(5259), 263-267 (1996).

2. R. J. Samulski, L. S. Chang and T. Shenk, Helper-free stocks of recombinant adeno-associated viruses: Normal integration does not require viral gene expression, $J$ Virol. 63(9), 3822-3828 (1989).

3. A. J. Lotery, T. A. Derksen, S. R. Russell, R. F. Mullins, S. Sauter, L. M. Affatigato, E. M. Stone and B. L. Davidson, Gene transfer to the nonhuman primate retina with recombinant feline immunodeficiency virus vectors, Hum Gene Ther. 13(6), 689-696 (2002).

4. J. Bennett, A. M. Maguire, A. V. Cideciyan, M. Schnell, E. Glover, V. Anand, T. S. Aleman, N. Chirmule, A. R. Gupta, Y. Huang, G. P. Gao, W. C. Nyberg, J. Tazelaar, J. Hughes, J. M. Wilson and S. G. Jacobson, Stable transgene expression in rod photoreceptors after recombinant adeno-associated virus-mediated gene transfer to monkey retina, Proc Natl Acad Sci U S A. 96(17), 9920-9925 (1999).

5. Foundation Fighting Blindness (2003) http://www.blindness.org/content.asp?id=208

6. N. Loewen, D. A. Leske, J. D. Cameron, Y. Chen, T. Whitwam, R. D. Simari, W. L. Teo, M. P. Fautsch, E. M. Poeschla and J. M. Holmes, Long-term retinal transgene expression with fiv versus adenoviral vectors, Mol Vis. 10, 272-280 (2004).

7. Y. Ikeda, Y. Goto, Y. Yonemitsu, M. Miyazaki, T. Sakamoto, T. Ishibashi, T. Tabata, Y. Ueda, M. Hasegawa, S. Tobimatsu and K. Sueishi, Simian immunodeficiency virus-based lentivirus vector for retinal gene transfer: A preclinical safety study in adult rats, Gene Ther. 10(14), 1161-1169 (2003).

8. K. Takahashi, T. Luo, Y. Saishin, J. Sung, S. Hackett, R. K. Brazzell, M. Kaleko and P. A. Campochiaro, Sustained transduction of ocular cells with a bovine immunodeficiency viral vector, Hum Gene Ther. 13(11), 1305-1316 (2002).

9. L. F. Wong, M. Azzouz, L. E. Walmsley, Z. Askham, F. J. Wilkes, K. A. Mitrophanous, S. M. Kingsman and N. D. Mazarakis, Transduction patterns of pseudotyped lentiviral vectors in the nervous system, Mol Ther. 9(1), 101-111 (2004).

10. T. Kafri, H. van Praag, L. Ouyang, F. H. Gage and I. M. Verma, A packaging cell line for lentivirus vectors, J Virol. 73(1), 576-584 (1999).

11. P. Escarpe, N. Zayek, P. Chin, F. Borellini, R. Zufferey, G. Veres and V. Kiermer, Development of a sensitive assay for detection of replication-competent recombinant lentivirus in large-scale hiv-based vector preparations, Mol Ther. 8(2), 332-341 (2003).

12. H. Miyoshi, U. Blomer, M. Takahashi, F. H. Gage and I. M. Verma, Development of a self-inactivating lentivirus vector, $J$ Virol. 72(10), 8150-8157 (1998).

13. S. C. Barry, B. Harder, M. Brzezinski, L. Y. Flint, J. Seppen and W. R. Osborne, Lentivirus vectors encoding both central polypurine tract and posttranscriptional regulatory element provide enhanced transduction and transgene expression, Hum Gene Ther. 12(9), 1103-1108 (2001).

14. V. Zennou, C. Petit, D. Guetard, U. Nerhbass, L. Montagnier and P. Charneau, Hiv-1 genome nuclear import is mediated by a central DNA flap, Cell. 101(2), 173-185 (2000).

15. A. Limon, N. Nakajima, R. Lu, H. Z. Ghory and A. Engelman, Wild-type levels of nuclear localization and human immunodeficiency virus type 1 replication in the absence of the central DNA flap, $J$ Virol. 76(23), 12078-12086 (2002).

16. R. Zufferey, J. E. Donello, D. Trono and T. J. Hope, Woodchuck hepatitis virus posttranscriptional regulatory element enhances expression of transgenes delivered by retroviral vectors, $J$ Virol. 73(4), 28862892 (1999).

17. M. Takahashi, H. Miyoshi, I. M. Verma and F. H. Gage, Rescue from photoreceptor degeneration in the rd mouse by human immunodeficiency virus vector-mediated gene transfer, $J$ Virol. 73(9), 7812-7816 (1999).

18. J. W. Bainbridge, C. Stephens, K. Parsley, C. Demaison, A. Halfyard, A. J. Thrasher and R. R. Ali, In vivo gene transfer to the mouse eye using an hiv-based lentiviral vector; efficient long-term transduction of corneal endothelium and retinal pigment epithelium, Gene Ther. 8(21), 1665-1668 (2001).

19. B. A. van Adel, C. Kostic, N. Deglon, A. K. Ball and Y. Arsenijevic, Delivery of ciliary neurotrophic factor via lentiviral-mediated transfer protects axotomized retinal ganglion cells for an extended period of time, Hum Gene Ther. 14(2), 103-115 (2003).

20. V. Sandrin, S. J. Russell and F. L. Cosset, Targeting retroviral and lentiviral vectors, Curr Top Microbiol Immunol. 281, 137-178 (2003). 
21. J. C. Burns, T. Friedmann, W. Driever, M. Burrascano and J. K. Yee, Vesicular stomatitis virus g glycoprotein pseudotyped retroviral vectors: Concentration to very high titer and efficient gene transfer into mammalian and nonmammalian cells, Proc Natl Acad Sci U S A. 90(17), 8033-8037 (1993).

22. Y. Kang, C. S. Stein, J. A. Heth, P. L. Sinn, A. K. Penisten, P. D. Staber, K. L. Ratliff, H. Shen, C. K. Barker, I. Martins, C. M. Sharkey, D. A. Sanders, P. B. McCray, Jr. and B. L. Davidson, In vivo gene transfer using a nonprimate lentiviral vector pseudotyped with ross river virus glycoproteins, $J$ Virol. 76(18), 9378-9388 (2002).

23. N. D. Mazarakis, M. Azzouz, J. B. Rohll, F. M. Ellard, F. J. Wilkes, A. L. Olsen, E. E. Carter, R. D. Barber, D. F. Baban, S. M. Kingsman, A. J. Kingsman, K. O'Malley and K. A. Mitrophanous, Rabies virus glycoprotein pseudotyping of lentiviral vectors enables retrograde axonal transport and access to the nervous system after peripheral delivery, Hum Mol Genet. 10(19), 2109-2121 (2001).

24. A. Auricchio, G. Kobinger, V. Anand, M. Hildinger, E. O'Connor, A. M. Maguire, J. M. Wilson and J. Bennett, Exchange of surface proteins impacts on viral vector cellular specificity and transduction characteristics: The retina as a model, Hum Mol Genet. 10(26), 3075-3081 (2001).

25. G. Duisit, H. Conrath, S. Saleun, S. Folliot, N. Provost, F. L. Cosset, V. Sandrin, P. Moullier and F. Rolling, Five recombinant simian immunodeficiency virus pseudotypes lead to exclusive transduction of retinal pigmented epithelium in rat, Mol Ther. 6(4), 446-454 (2002).

26. D. A. Sanders, No false start for novel pseudotyped vectors, Curr Opin Biotechnol. 13(5), 437-442 (2002).

27. C. Kostic, F. Chiodini, P. Salmon, M. Wiznerowicz, N. Deglon, D. Hornfeld, D. Trono, P. Aebischer, D. F. Schorderet, F. L. Munier and Y. Arsenijevic, Activity analysis of housekeeping promoters using selfinactivating lentiviral vector delivery into the mouse retina, Gene Ther. 10(9), 818-821 (2003).

28. H. Miyoshi, M. Takahashi, F. H. Gage and I. M. Verma, Stable and efficient gene transfer into the retina using an hiv-based lentiviral vector, Proc Natl Acad Sci U S A. 94(19), 10319-10323 (1997).

29. J. Jakobsson, C. Ericson, M. Jansson, E. Bjork and C. Lundberg, Targeted transgene expression in rat brain using lentiviral vectors, J Neurosci Res. 73(6), 876-885 (2003).

30. L. P. de Almeida, D. Zala, P. Aebischer and N. Deglon, Neuroprotective effect of a cntf-expressing lentiviral vector in the quinolinic acid rat model of huntington's disease, Neurobiol Dis. 8(3), 433-446 (2001).

31. L. Sastry, T. Johnson, M. J. Hobson, B. Smucker and K. Cornetta, Titering lentiviral vectors: Comparison of DNA, rna and marker expression methods, Gene Ther. 9(17), 1155-1162 (2002).

32. A. R. Harvey, W. Kamphuis, R. Eggers, N. A. Symons, B. Blits, S. Niclou, G. J. Boer and J. Verhaagen, Intravitreal injection of adeno-associated viral vectors results in the transduction of different types of retinal neurons in neonatal and adult rats: A comparison with lentiviral vectors, Mol Cell Neurosci. 21(1), 141-157 (2002).

33. L. D. Carter-Dawson and M. M. LaVail, Rods and cones in the mouse retina. Ii. Autoradiographic analysis of cell generation using tritiated thymidine, J Comp Neurol. 188(2), 263-272 (1979).

34. K. Mervin and J. Stone, Developmental death of photoreceptors in the $\mathrm{c} 57 \mathrm{bl} / 6 \mathrm{j}$ mouse: Association with retinal function and self-protection, Exp Eye Res. 75(6), 703-713 (2002).

35. D. A. Coil and A. D. Miller, Phosphatidylserine is not the cell surface receptor for vesicular stomatitis virus, J Virol. 78(20), 10920-10926 (2004).

36. O. Grüter, C.Kostic, M.Tekaya, D.F. Schorderet, L.Zografos, F.L. Munier, Y.Arsenijevic, Potential improvement of lentiviral gene transfer by weakening the extracellular matrix, ARVO poster \#B97 (2004). 